\title{
Effect of intraoperative hypovolemic phlebotomy on transfusion and clinical outcomes in patients undergoing hepatectomy: a retrospective cohort study
}

\section{Effet de la phlébotomie hypovolémique peropératoire sur la transfusion et les résultats cliniques des patients subissant une hépatectomie : une étude de cohorte rétrospective}

\author{
Maher Al Khaldi, MD • Filip Gryspeerdt, MD • François Martin Carrier, MD, MSc, \\ FRCPC · Claudia Bouchard • Ève Simoneau, MD, PhD, FRCSC - Zhixia Rong, MD, MSc, \\ FRCPC • Marylène Plasse, MD, FRCPC • Richard Létourneau, MD, FRCPC • \\ Michel Dagenais, MD, MSc, FRCSC • André Roy, MD, FRCSC · Réal Lapointe, MD, \\ FRCSC • Luc Massicotte, MD, FRCPC · Franck Vandenbroucke-Menu, MD, FRCSC • \\ Benjamin Rioux-Massé, MD, FRCPC $\cdot$ Simon Turcotte, MD, MSc, FRCSC
}

Received: 30 October 2020/Revised: 3 December 2020/Accepted: 23 December 2021/Published online: 4 May 2021

(c) The Author(s) 2021

\begin{abstract}
Background There is no consensus on how to best achieve a low central venous pressure during hepatectomy for the purpose of reducing blood loss and red blood cell (RBC) transfusions. We analyzed the associations between
\end{abstract}

Maher Al Khaldi and Filip Gryspeerdt-Co-first authors, equal contribution.

Supplementary Information The online version of this article (https://doi.org/10.1007/s12630-021-01958-8) contains supplementary material, which is available to authorized users.

M. Al Khaldi, MD - F. Gryspeerdt, MD - È. Simoneau, MD, $\mathrm{PhD}$, FRCSC $\cdot$ Z. Rong, MD, MSc, FRCPC $\cdot$ M. Plasse, MD, FRCPC $\cdot$ R. Létourneau, MD, FRCPC $\cdot$ M. Dagenais, MD, MSc, FRCSC - A. Roy, MD, FRCSC - R. Lapointe, MD, FRCSC - F. Vandenbroucke-Menu, MD, FRCSC

S. Turcotte, MD, MSc, FRCSC ( $\square)$

Hepatopancreatobiliary Surgery and Liver Transplantation Service, Department of Surgery, Centre hospitalier de l'Université de Montréal (CHUM), Pavillon R. 900, rue StDenis, porte R10.430, Montreal, QC H2X 0A9, Canada

e-mail: simon.turcotte.1@umontreal.ca

F. M. Carrier, MD, MSc, FRCPC

Department of Anesthesiology, Centre hospitalier de

l’Université de Montréal (CHUM), Montreal, QC, Canada

Critical Care Service, Department of Medicine, Centre hospitalier de l'Université de Montréal (CHUM), Montreal, QC, Canada intraoperative hypovolemic phlebotomy (IOHP), transfusions, and postoperative outcomes in cancer patients undergoing hepatectomy.

Methods Using surgical and transfusion databases of patients who underwent hepatectomy for cancer at one institution (11 January 2011 to 22 June 2017), we retrospectively analyzed associations between IOHP and $R B C$ transfusion on the day of surgery (primary outcome), and with total perioperative transfusions, intraoperative blood loss, and postoperative complications (secondary
C. Bouchard · B. Rioux-Massé, MD, FRCPC
Department of Hematology-Transfusion Medicine, Centre hospitalier de l'Université de Montréal (CHUM), Montreal, QC, Canada
L. Massicotte, MD, FRCPC
Department of Anesthesiology, Centre hospitalier de
l'Université de Montréal (CHUM), Montreal, QC, Canada 
outcomes). We fitted logistic regression models by inverse probability of treatment weighting to adjust for confounders and reported adjusted odds ratio (aOR).

Results There were 522 instances of IOHP performed during 683 hepatectomies, with a mean (standard deviation) volume of 396 (119) $\mathrm{mL}$. The IOHP patients had a $6.9 \%$ transfusion risk on the day of surgery compared with $12.4 \%$ in non-IOHP patients (aOR, 0.53; 95\% confidence interval [CI], 0.29 to 0.98; $P=0.04$ ). Total perioperative RBC transfusion tended to be lower in IOHP patients compared with non-IOHP patients $(14.9 \%$ vs $22.4 \%$, respectively; $a O R, 0.72 ; 95 \%$ CI, 0.44 to 1.16 ; $P=0.18)$. In patients with a predicted risk of $\geq 47.5 \%$ perioperative $R B C$ transfusion, $24.6 \%$ were transfused when IOHP was used compared with $56.5 \%$ without IOHP. The incidence of severe postoperative complications (Clavien-Dindo scores $\geq 3$ ) was similar in patients whether or not IOHP was performed (15\% vs $16 \%$ respectively; aOR, 0.97; 95\% CI, 0.53 to $1.54 ; P=0.71$ ). Conclusions The use of IOHP during hepatectomy was associated with less RBCs transfused on the same day of surgery. Trials comparing IOHP with other techniques to reduce blood loss and transfusion are needed in liver surgery.

\section{Résumé}

Contexte Il n'existe pas de consensus quant à la meilleure façon d'obtenir une pression veineuse centrale basse pendant une hépatectomie dans le but de réduire les pertes et les transfusions sanguines. Nous avons analyséles associations entre la phlébotomie hypovolémique peropératoire, les transfusions, et les résultats cliniques postopératoires chez les patients qui subissent une hépatectomie pour cancer.

Méthode À l'aide de bases de données chirurgicales et transfusionnelles de patients ayant subi une hépatectomie pour cancer dans un seul établissement (du 11 janvier 2011 au 22 juin 2017), nous avons rétrospectivement analysé les associations entre la phlébotomie hypovolémique peropératoire et les transfusions érythrocytaires le jour de la chirurgie (critère d'évaluation principal) et avec les transfusions périopératoires totales, les pertes sanguines peropératoires, et les complications postopératoires (critères d'évaluation secondaires). Nous avons utilisé des modèles de régression logistique avec pondération de probabilité inverse de traitement afin de tenir compte des facteurs de confusion et rapporté les rapports de cotes ajustés (RCa).

Résultats Il y a eu 522 phlébotomies hypovolémiques peropératoires exécutées au cours de 683 hépatectomies, avec un volume moyen (écart type) de 396 (119) mL. Les patients ayant eu une phlébotomie hypovolémique peropératoire avaient un risque transfusionnel de 6,9\% le jour de la chirurgie, comparativement à $12,4 \%$ pour les patients sans phlébotomie (RCa, 0,53; intervalle de confiance [IC] de $95 \%, 0,29$ à 0,98; P = 0,04). Les transfusions périopératoires totales d'érythrocytes tendaient à être moins fréquentes chez les patients ayant subi une phlébotomie hypovolémique peropératoire par rapport aux patients sans phlébotomie (14,9\% vs 22,4\%, respectivement; $R C a, 0,72$; IC $95 \%, 0,44$ à 1,16; $P=$ 0,18). Pour les patients présentant un risque prédit de transfusion périopératoire d'érythrocytes $\geq$ à 47,5\%, 24,6 $\%$ de ceux qui ont eu une phlébotomie hypovolémique peropératoire ont été transfusés, comparativement à 56,5 $\%$ sans phlébotomie. L'incidence des complications postopératoires graves (scores de Clavien-Dindo $\geq 3$ ) était semblable chez tous les patients, avec ou sans phlébotomie hypovolémique peropératoire (15\% vs $16 \%$ respectivement; $R C a, 0,97 ; I C 95 \%, 0,53$ à 1,$54 ; P=$ 0,71).

Conclusions L'utilisation de la phlébotomie hypovolémique peropératoire pendant une hépatectomie était associée à un moins grand nombre de transfusions érythrocytaires le jour de la chirurgie. Des études qui compareront la phlébotomie hypovolémique peropératoire à d'autres techniques visant à réduire les pertes et les transfusions sanguines sont nécessaires en chirurgie hépatique.

Partial hepatectomy is the mainstay of liver cancer treatment in patients with a curative intent. Acceptable postoperative morbidity and mortality rates have been achieved and associated with long-term survival. ${ }^{1,2}$ Nevertheless, the liver has a complex and rich vascular anatomy. Resection is prone to bleeding and subsequent need for perioperative red blood cell (RBC) transfusions. With improved surgical techniques and perioperative management, transfusion rates have dropped from as high as $83 \%$ in the 1980 s to $22 \%$ in more recent series. ${ }^{3-5}$ Blood loss and allogeneic RBC transfusions have been associated with a high postoperative complication rate, low yet non-negligible risk of infectious disease transmission, earlier cancer recurrence and related mortality, and significant costs. . $^{3,6-8}$

Multiple strategies and patient blood management (PBM) protocols have been proposed to minimize the potential detrimental effects of RBC transfusion on patient outcomes. $^{9-18}$ The strongest predictors of perioperative $\mathrm{RBC}$ transfusion are a preoperative hemoglobin $(\mathrm{Hgb})<$ $125 \mathrm{~g} \cdot \mathrm{L}^{-1}$, major liver resection ( $\geq$ four segments), and surgery for primary (as opposed to metastatic) liver 
cancer. ${ }^{4}$ Maintaining a low central venous pressure (CVP) during hepatectomy has been considered the main technique available to anesthesiologists to reduce intraoperative blood loss, a major determinant of transfusion. ${ }^{4,15,19-21}$ Low CVP has been achieved with fluid restriction, the use of vasodilators, and intraoperative hypovolemic phlebotomy (IOHP), which entails the removal of whole blood without volume replacement prior to liver transection. No large randomized-controlled trials have established a standard for the use of any low CVP technique.

Although previous studies, reporting on fewer than 300 patients in total, have supported that IOHP is safe, the technique's use varied considerably between studies and RBC transfusion rates ranged from $2.0 \%$ to $22.5 \% .^{15,19,22,23}$ In the present study, our primary objective was to analyze the associations between IOHP and RBC transfusion on the day of surgery, and our secondary objectives were to examine total perioperative RBC transfusion, intraoperative blood loss, and postoperative complications.

\section{Methods}

\section{Design and setting}

After approval from the institutional research ethics board (no. 18.034; 30 August 2018), we conducted a retrospective cohort study at the Centre hospitalier de l'Université de Montréal evaluating the associations between IOHP and perioperative RBC transfusion, intraoperative blood loss, post-hepatectomy complications, and survival. All patients had provided written informed consent to be part of a prospectively maintained surgical database to be analyzed in institutionally approved research projects.

\section{Patient selection}

Inclusion criteria included adult patients undergoing elective hepatectomy for primary (hepatocellular carcinoma and intrahepatic cholangiocarcinoma) or liver metastases between 11 January 2011 and 22 June 2017. We excluded hepatectomy for gallbladder cancer, extrahepatic cholangiocarcinoma, and benign hepatic tumours.

\section{Intraoperative management}

All hepatic resections were performed by a team of seven hepatopancreatobiliary surgeons. Colorectal surgeons assisted when a combined resection was performed for a primary colorectal cancer with synchronous liver metastases. Liver parenchymal transection was performed with ultrasonography guidance generally using crushclamp dissection, ultrasonic energy devices, and intrahepatic pedicle ligation. Hemostasis was generally accomplished with argon beam coagulation. Intermittent atraumatic hepatic hilar clamping (Pringle maneuver) was used at the discretion of the surgeons to control bleeding during parenchymal transection. Blood salvage was used at the discretion of the surgeon, generally when intraoperative bleeding exceeded expected volume. As per institutional standards, tranexamic acid was not used in these patients undergoing elective liver resection.

All operations were performed under standard balanced general anesthesia using invasive pressure monitoring and a central multi-lumen venous access including CVP monitoring. Thoracic epidural analgesia was used in most patients, with the intraoperative use of local anesthetics at the anesthesiologist's discretion; for other patients, intrathecal morphine $(0.05-0.5 \mathrm{mg})$ was used as the preferred postoperative analgesia modality. A low CVP management strategy was employed for all patients as tolerated. The use of IOHP was at the discretion of the anesthesiologist and generally restricted to patients with $\mathrm{Hgb}$ levels $>85 \mathrm{~g} \cdot \mathrm{L}^{-1}$ and with glomerular filtration rates $\left(\right.$ GFR) $>60 \mathrm{~mL} \cdot \mathrm{min}^{-1}$, as previously published. ${ }^{24} \mathrm{Using}$ the central venous catheter, whole blood was harvested over approximately $15 \mathrm{~min}$ before hepatic resection was started. The targeted IOHP volume was $5-10 \mathrm{~mL} \cdot \mathrm{kg}^{-1}$, with the aim to reduce CVP by approximately $40 \%$ (no absolute value goal). Blood was withdrawn passively by gravity, collected in citrate-containing solution bags, and kept for up to eight hours at $4^{\circ} \mathrm{C}$ or four hours at room temperature (no agitator). Upon completion of hepatic resection, the autologous blood was reinfused into the patient (or before in cases of major bleeding during the resection).

Exposure and outcomes

The exposure of interest for this study was the use of IOHP. The primary outcome examined was RBC transfusion during and after the surgery on the same day of surgery. The secondary outcomes included any RBC transfusions throughout the entire hospital stay (defined as perioperative transfusions), intraoperative blood loss, postoperative complications (defined using the Clavien-Dindo classification), ${ }^{25}$ 90-day mortality, and one-year overall survival. Intraoperative blood loss was estimated based on the volume of suctioned fluid minus irrigation fluid and by consensus between the surgeon and the anesthesiologist. Intraoperative and postoperative $\mathrm{RBC}$ transfusions were administered based on intraoperative blood loss, hemodynamic instability, or a $\mathrm{Hgb}$ threshold $\leq 70 \mathrm{~g} \cdot \mathrm{L}^{-1}$ 
( $\leq 80 \mathrm{~g} \cdot \mathrm{L}^{-1}$ in patients with coronary disease). Posthepatectomy liver failure was graded according to the International Study Group of Liver Surgery. ${ }^{26}$ After discharge, patients were followed-up at four to six weeks postoperatively, then every four to six months with dedicated imaging.

\section{Covariables}

Variables were selected for descriptive purposes and as potential confounders. Patient baseline characteristics were recorded as well as the most recent (within three months of surgery) preoperative $\mathrm{Hgb}$, creatinine $(\mathrm{Cr})$, international normalized ratio (INR), and platelet count. Potential confounders of the association between IOHP and outcomes selected before conducting any analyses included age, sex, preoperative $\mathrm{Hgb}$ and $\mathrm{Cr}$, second staged resection (any liver resection when a previous one was done), major resection (defined as a resection of four or more segments), primary liver cancer, combined liver and gastrointestinal (GI) surgery, the use of epidural analgesia, and a planned laparoscopic surgery. We used the three-point perioperative transfusion risk score (TRS) for stratified descriptive analyses, where one point is cumulatively attributed to a patient presenting with: 1) $\left.\mathrm{Hgb} \leq 125 \mathrm{~g} \cdot \mathrm{L}^{-1}, 2\right)$ primary liver malignancy, and 3) major hepatic resection of $\geq$ four segments. A TRS of 0 corresponds to a low risk of perioperative transfusion (14.1\%), 1 to a moderate risk (27.3\%), 2 to a high risk $(47.5 \%)$, and 3 to a very high risk $(62.0 \%){ }^{4}$

\section{Data management}

The transfusion data were extracted from the blood bank database (TraceLine $\left.{ }^{\circledR}\right)$, linked to the provincial blood service database (Héma-Québec). The anesthesia data on IOHP and estimated blood loss were extracted from the electronic health record (Oacis software). Survival data were last updated on 26 June 2019. All data were merged in a unique research database that was securely stored on our research centre server.

\section{Statistical analyses}

Statistical analyses were pre-planned to limit bias. A convenience sample size was used based on existing patient entries in our database. Descriptive data were reported as mean (standard deviation [SD]) for continuous variables, median [interquartile range (IQR)] for skewed distributions, and as proportions for categorical variables. We reported the median overall survival as Kaplan-Meier estimates. Our primary analysis was a logistic regression to estimate the association between IOHP and RBC transfusion. We fitted models by generalized estimating equations using an exchangeable correlation matrix and robust sandwich-type standard errors to consider intrapatient correlation (75 patients had two different liver resections within the data set). We fitted unadjusted models and adjusted models by the inverse probability of treatment weighting (IPTW) using a propensity score of IOHP. The propensity score was estimated with the aforementioned potential confounders. ${ }^{4}$ For the one-year overall survival analysis, we fitted marginal Cox models with robust standard errors to take into account intrapatient correlation. We censored patients who had more than one liver resection in our data set at the second surgery and then censored all observations at one year. We verified the proportionality assumption by a visual inspection of the Schoenfeld residuals and by a Harrel and Lee test. ${ }^{27}$

Multivariable modelling was used for all outcomes to explore the effect of other determinants and as sensitivity analyses of the IPTW model. The same confounders were used without epidural analgesia and planned laparoscopic surgery as predictors of the exposure for power purposes ( $a$ priori decision). ${ }^{28}$ We verified the presence of multicollinearity using the variance inflation factor. Stratified descriptive analyses of the proportion of patients transfused according to each stratum of the TRS score as well as stratified analyses based on the volume of IOHP were conducted. The alpha level was 0.05 and results are reported with $95 \%$ confidence intervals (CIs). All missing values are reported in the tables. Analyses were performed using R software (R Core Team, version 3.6.2).

\section{Results}

\section{Patient characteristics}

There were 608 patients who underwent 683 hepatectomies (75 patients had a second liver resection). Baseline patient characteristics are summarized in Table 1. Of 683 hepatectomies, $553(81 \%)$ and $130(19 \%)$ were for liver metastases and primary liver cancers, respectively. The mean (SD) preoperative $\mathrm{Hgb}$ was 131 (15) $\mathrm{g} \cdot \mathrm{L}^{-1}$. Major liver resections ( $\geq$ four segments) were performed in 229 of the 683 (34\%) hepatectomies. Using the TRS, ${ }^{4} 145$ of $683(22 \%)$ surgeries were performed in patients considered at high or very high risk of perioperative transfusion. Intraoperative bleeding was controlled with intermittent hepatic hilar clamping (Pringle maneuver) in 28\% (180/ $683)$ of cases. Blood salvage was used in 7\% (46/683) of cases. Most cases were performed by laparotomy, with epidural analgesia used in 92\% (626/683) of cases.

There were $522(76.4 \%)$ IOHP performed in 683 hepatectomies with a mean (SD) phlebotomy volume of 
Table 1 Patient baseline characteristics

\begin{tabular}{|c|c|c|c|c|}
\hline Variable & $\begin{array}{l}\text { All } \\
(n=683)\end{array}$ & $\begin{array}{l}\text { No IOHP } \\
(n=161)\end{array}$ & $\begin{array}{l}\text { IOHP } \\
(n=522)\end{array}$ & SMD \\
\hline \multicolumn{5}{|l|}{ Baseline characteristics } \\
\hline Age & $63(11)$ & $62(11)$ & $63(11)$ & 0.11 \\
\hline Sex, male & $432(63 \%)$ & $102(63 \%)$ & $330(63 \%)$ & 0.00 \\
\hline Preoperative hemoglobin $\left(\mathrm{g} \cdot \mathrm{L}^{-1}\right)$ & $131(15)$ & $129(18)$ & $131(14)$ & 0.15 \\
\hline Preoperative creatinine $\left(\mu \mathrm{mol} \cdot \mathrm{L}^{-1}\right)$ & 74 [51-97] & 76 [64-87] & $73[63-86]$ & 0.16 \\
\hline Preoperative INR $>1.2 *$ & $22(4 \%)$ & $8(5 \%)$ & $14(3 \%)$ & 0.12 \\
\hline Preoperative platelets $\uparrow\left(\mathrm{x} 10^{9} \cdot \mathrm{L}^{-1}\right)$ & $204[168-251]$ & $206[158-253]$ & $204[168-251]$ & 0.09 \\
\hline Primary liver cancer & $130(19 \%)$ & $25(16 \%)$ & $105(20 \%)$ & 0.12 \\
\hline Hepatocellular carcinoma & $85(13 \%)$ & $18(11 \%)$ & $67(13 \%)$ & \\
\hline Second liver resection & $75(11 \%)$ & $12(7 \%)$ & $63(12 \%)$ & 0.16 \\
\hline \multirow[t]{4}{*}{ Transfusion risk score ${ }^{\S}$} & 0: $249(37 \%)$ & 0: $68(42 \%)$ & $0: 181(35 \%)$ & 0.16 \\
\hline & 1: $289(42 \%)$ & 1: $66(41 \%)$ & 1: $223(43 \%)$ & 0.04 \\
\hline & 2: $133(20 \%)$ & $2: 23(14 \%)$ & 2: $110(21 \%)$ & 0.18 \\
\hline & 3: $12(2 \%)$ & $3: 4(2 \%)$ & $3: 8(2 \%)$ & 0.07 \\
\hline \multicolumn{5}{|l|}{ Intraoperative characteristics } \\
\hline Phlebotomy volume $(\mathrm{mL})$ & & & $396(119)^{\bullet}$ & \\
\hline Epidural analgesia & $626(92 \%)$ & $134(83 \%)$ & $492(94 \%)$ & 0.35 \\
\hline Laparoscopic surgery & $71(10 \%)^{\#}$ & $26(16 \%)$ & $45(8 \%)$ & 0.27 \\
\hline Major resection ( $\geq 4$ segments) & $229(34 \%)$ & $41(25 \%)$ & $188(36 \%)$ & 0.23 \\
\hline Combined GI tract surgery** & $47(7 \%)$ & $22(14 \%)$ & $25(5 \%)$ & 0.31 \\
\hline Hepaticojejunostomy & $13(2 \%)$ & $1(1 \%)$ & $12(2 \%)$ & 0.14 \\
\hline Pringle maneuver ${ }^{\dagger \dagger}$ & $180(28 \%)$ & $36(24 \%)$ & $144(29 \%)$ & 0.11 \\
\hline Blood salvage & $46(7 \%)$ & $8(5 \%)$ & $38(7 \%)$ & 0.10 \\
\hline Duration of surgery ${ }^{*}(\mathrm{~min})$ & $190[140-240]$ & 185 [140-235] & $190[145-240]$ & 0.06 \\
\hline
\end{tabular}

Continuous variables are reported as mean (standard deviation) or median [interquartile range] as indicated. SMD is used to numerically evaluate the differences between patients grouped by IOHP $v s$ no IOHP.

*74 missing values (15 in the no phlebotomy group and 59 in the phlebotomy group)

${ }^{\dagger} 73$ missing values (18 in the no phlebotomy group and 55 in the phlebotomy group)

Included in the primary liver cancer proportion.

${ }^{\S}$ One point is given per risk factors: i) preoperative $\mathrm{Hgb} \leq 125 \mathrm{~g} \cdot \mathrm{L}$, ii) primary liver malignancy, and iii) resection of $\geq 4$ segments ${ }^{4}$

22 missing values out of 522 patients who were exposed to a phlebotomy

\#28 (39\%) converted to open surgeries

**Either concomitant oncological surgery (42) or any other indication (5)

${ }^{\dagger} 33$ missing values (10 in the no phlebotomy group and 23 in the phlebotomy group)

*6 missing values ( 2 in the no phlebotomy group and 4 in the phlebotomy group)

$\mathrm{GI}=$ gastrointestinal; Hgb = hemoglobin; INR = international normalized ratio; IOHP = intraoperative hypovolemic phlebotomy; SMD = standardized mean difference.

$396(119) \mathrm{mL}$, representing a median [IQR] of 5.3 [4.1-6.4] $\mathrm{mL} \cdot \mathrm{kg}^{-1}$ of body weight. As shown in Table 1 , there were more major hepatectomies, open procedures, and use of epidural analgesia in IOHP patients than non-IOHP patients. Combined liver and GI resections were performed less frequently in IOHP patients (25/522; $4.8 \%)$ than non-IOHP patients $(22 / 161 ; 13.7 \%)$. The average operative time and the use of blood salvage were not numerically different whether or not IOHP was used, while the use of Pringle maneuvers was slightly more frequent in patients with IOHP.

\section{Transfusion and IOHP}

As shown in Table 2, 8.2\% of patients received RBC transfusions on the day of surgery and $16.7 \%$ perioperatively, during their hospital stay. In transfused patients, a median [IQR] of 2 [1-3] RBC units were 
Table 2 Postoperative outcomes

\begin{tabular}{|c|c|c|c|}
\hline Outcomes & $\begin{array}{l}\text { All } \\
(n=683)\end{array}$ & $\begin{array}{l}\text { No IOHP } \\
(n=161)\end{array}$ & $\begin{array}{l}\text { IOHP } \\
(n=522)\end{array}$ \\
\hline Patients transfused on the day of surgery & $56(8.2 \%)$ & $20(12.4 \%)$ & $36(6.9 \%)$ \\
\hline Patients transfused perioperatively & $114(16.7 \%)$ & $36(22.4 \%)$ & $78(14.9 \%)$ \\
\hline Perioperative transfusions among patients transfused & $2[1-3]$ & $2[1-4]$ & $2[1-3]$ \\
\hline Intraoperative bleeding, $\mathrm{mL}$ & $500[250-800]$ & $300[200-700]^{*}$ & $500[300-800]$ \\
\hline Length of stay, days & $7[5-9]$ & $7[6-10]$ & $7[5-9]$ \\
\hline Patients with $\geq 1$ severe complication (Clavien-Dindo III, IV, V) ${ }^{25}$ & $95(13.9 \%)$ & $23(14.3 \%)$ & $72(13.7 \%)$ \\
\hline Liver failure, any grade ${ }^{26}$ & $29(4.2 \%)$ & $9(5.6 \%)$ & $20(3.8 \%)$ \\
\hline Postoperative 90-day mortality & $10(1.5 \%)$ & $3(1.9 \%)$ & $7(1.3 \%)$ \\
\hline 1-year mortality, all causes ${ }^{\dagger}$ & $51(8.3 \%)$ & $15(9.5 \%)$ & $36(7.5 \%)$ \\
\hline Median $(95 \% \mathrm{CI})^{*}$ overall survival, years & $4.8(4.3$ to 5.7$)$ & $4.6(3.8$ to 6.0$)$ & $5.1(4.2$ to 6.2$)$ \\
\hline
\end{tabular}

Continuous variables are reported as median $[\mathrm{IQR}]$ as indicated.

*3 missing values

'Based on 608 non-duplicated patients in the whole cohort, 158 in the no IOHP group and 482 in the IOHP group (groups do not sum up because some patients had two surgeries in each group)

${ }^{*}$ By Kaplan-Meier with $95 \%$ CIs

$\mathrm{CI}=$ confidence interval; IOHP = intraoperative hypovolemic phlebotomy; IQR = interquartile range.

Fig. 1 Red blood cell transfusions. A) Patient transfusion rates on the day of surgery (dashed lines) and perioperatively during the entire hospital stay (bar height). B) Predicted (grey) perioperative transfusion rates in patients categorized by the three-point transfusion risk score (TRS), ${ }^{4}$ and observed transfusion rates according to intraoperative hypovolemic phlebotomy (IOHP) status.

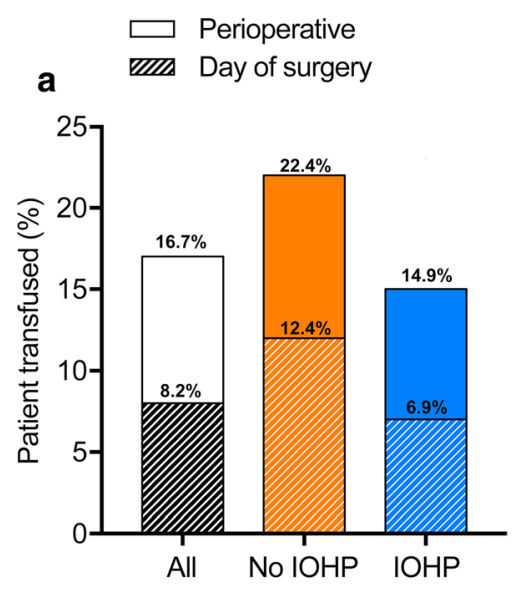

b

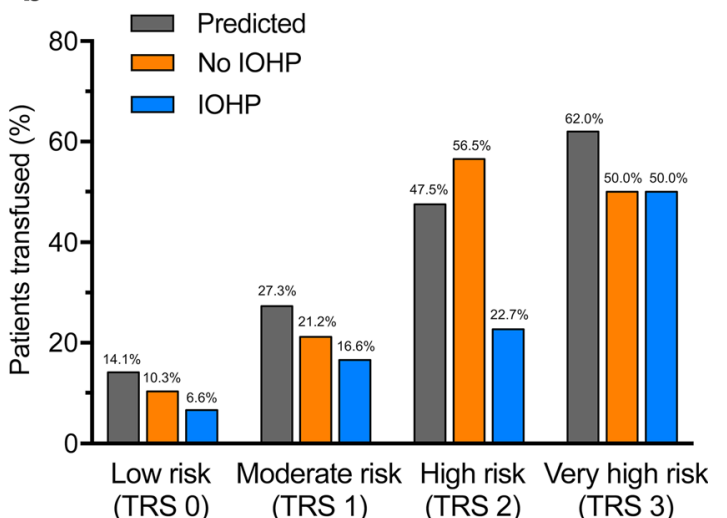

transfused perioperatively. Of the 522 IOHP patients, 36 $(6.9 \%)$ were transfused on the day of surgery and 78 (14.9\%) perioperatively during the entire hospital stay, compared with $20(12.4 \%)$ and $36(22.4 \%)$ of the 161 nonIOHP patients, respectively (Fig. 1a). There were fewer perioperative transfusions than predicted in IOHP patients, as categorized by the three-point TRS; the non-IOHP patients were closer to the TRS predictions (Fig. 1b). In unadjusted analyses, IOHP was associated with fewer transfusions compared with non-IOHP patients (OR, 0.53; 95\% CI, 0.30 to $0.93 ; P=0.03$ ) on the same day of surgery (Table 3) and perioperatively (OR, 0.62; 95\% CI, 0.40 to $0.95 ; P=0.03$ ) (Table 4). After controlling for age, sex, preoperative $\mathrm{Hgb}$ and $\mathrm{Cr}$ levels, second liver resections, major resections, resections for primary liver cancer, combined GI tract surgery, a planned laparoscopic surgery, and the use of epidural analgesia, the adjusted effect suggested that IOHP was significantly associated with lower RBC transfusions on the same day of surgery (adjusted odds ratio [aOR], $0.53 ; 95 \% \mathrm{CI}, 0.29$ to $0.98 ; P=$ 0.04) (Table 3). A similar trend was observed for perioperative transfusions (aOR, $0.72 ; 95 \% \mathrm{CI}, 0.44$ to $1.16 ; P=0.18$ ) (Table 4). In unadjusted analysis, the use of IOHP was associated with higher reported blood loss $(\hat{\beta}$, $0.19 ; 95 \% \mathrm{CI}, 0.07$ to $0.32 ; P=0.003)$, an association no longer significant in adjusted analysis $(\hat{\beta}, 0.11 ; 95 \% \mathrm{CI}$, 0.02 to $0.33 ; P=0.11$ ) (see eTable 1 in the Electronic Supplemental Material [ESM]).

We explored the effect of confounders by multivariable sensitivity analyses. The use of IOHP tended to be 
Table 3 Association between baseline variables and transfusion on the day of surgery

\begin{tabular}{|c|c|c|}
\hline Variable & OR $(95 \% \mathrm{CI})$ & $P$ value \\
\hline \multicolumn{3}{|l|}{ Unadjusted (univariate analysis) } \\
\hline IOHP & $0.53(0.30$ to 0.93$)$ & 0.03 \\
\hline \multicolumn{3}{|c|}{ Adjusted (inverse probability of treatment weighting)* } \\
\hline IOHP & $0.53(0.29$ to 0.98$)$ & 0.04 \\
\hline \multicolumn{3}{|l|}{ Adjusted (multivariable analysis) } \\
\hline IOHP & $0.63(0.33$ to 1.23$)$ & 0.18 \\
\hline Age & $1.01(0.98$ to 1.04$)$ & 0.70 \\
\hline Sex, female & $1.00(0.52$ to 1.94$)$ & 0.99 \\
\hline Hemoglobin (per $10 \mathrm{~g} \cdot \mathrm{L}^{-1}$ ) & $0.62(0.51$ to 0.77$)$ & $<0.001$ \\
\hline Creatinine (per $10 \mu \mathrm{mol} \cdot \mathrm{L}^{-1}$ ) & $1.12(1.02$ to 1.24$)$ & 0.02 \\
\hline Second liver resection & $2.86(1.40$ to 5.86$)$ & 0.004 \\
\hline Major resection ( $\geq 4$ segments) & $2.37(1.30$ to 4.30$)$ & 0.005 \\
\hline Primary liver cancer & $2.36(1.08$ to 4.75$)$ & 0.03 \\
\hline Combined GI tract surgery & $0.69(0.20$ to 2.31$)$ & 0.55 \\
\hline
\end{tabular}

*Controlled for: age, sex, preoperative $\mathrm{Hgb}$ and $\mathrm{Cr}$, second liver resections, major resections ( $\geq 4$ segments), resections for primary liver cancer and combined gastrointestinal procedures. $n=683$ observations (56 events)

$\mathrm{CI}=$ confidence interval; $\mathrm{GI}=$ gastrointestinal; $\mathrm{IOHP}=$ intraoperative hypovolemic phlebotomy; OR = odds ratio.

Table 4 Association between baseline variables and total perioperative transfusion

\begin{tabular}{llr}
\hline Variable & OR $(95 \% \mathrm{CI})$ & $P$ value \\
\hline Unadjusted (univariate analysis) & $0.62(0.40$ to 0.95$)$ \\
IOHP & \\
Adjusted (inverse probability of treatment weighting)* & $0.72(0.44$ to 1.16$)$ \\
IOHP & \\
Adjusted (multivariable analysis) & $0.74(0.43$ to 1.26$)$ \\
IOHP & $1.00(0.98$ to 1.02$)$ \\
Age & $1.11(0.67$ to 1.83$)$ \\
Sex (female) & $0.59(0.50$ to 0.71$)$ \\
Hemoglobin (per $\left.10 \mathrm{~g} \cdot \mathrm{L}^{-1}\right)$ & $1.12(1.02$ to 1.23$)$ \\
Creatinine (per $\left.10 \mu \mathrm{mol} \cdot \mathrm{L}^{-1}\right)$ & $2.33(1.25$ to 4.38$)$ \\
Second resection & $2.15(1.36$ to 3.41$)$ \\
Major resection & $1.96(1.11$ to 3.46$)$ & 0.26 \\
Primary liver cancer & $2.54(1.13$ to 5.70$)$ \\
Combined GI tract surgery & 0.70 \\
\hline
\end{tabular}

*Controlled for: age, sex, preoperative Hgb and $\mathrm{Cr}$, second liver resections, major resections ( $\geq 4$ segments), resections for primary liver cancer, and combined gastrointestinal procedures.

$n=683$ observations (114 events).

$\mathrm{CI}=$ confidence interval; GI = gastrointestinal; IOHP = intraoperative hypovolemic phlebotomy; OR = odds ratio.

associated with lower same-day and perioperative transfusions, but this difference was not statistically significant (Tables 3 and 4). Additionally, we explored the risk of RBC transfusion and bleeding in the IOHP and non-IOHP patients stratified for the use of blood salvage (eTable 2, ESM). In the 46 patients in whom blood salvage was used, there were $7 / 38(18.4 \%)$ transfusions on the day of surgery in IOHP patients and 4/8 $(50.0 \%)$ in non-IOHP patients $(P=0.07)$. We also dichotomized phlebotomies as either small or large, based on the median volume normalized to patient weight $\left(5.3 \mathrm{~mL} \cdot \mathrm{kg}^{-1}\right)$. The volume of phlebotomies did not have any effect on transfusion on 
the day of surgery (eTables 3, ESM) or perioperatively (eTable 4, ESM). Nevertheless, small phlebotomies were associated with a greater risk of intraoperative bleeding $(\hat{\beta}$ $=0.18 ; 95 \% \mathrm{CI}, 0.06$ to 0.31$)$ whereas large phlebotomies were not ( $\hat{\beta}=0.09 ; 95 \%$ CI, 0.03 to 0.22 ) (eTable 5, ESM). Preoperative $\mathrm{Cr}$ levels, second and major liver resections, and hepatectomies for primary liver cancer were significantly associated with an increased risk of intraoperative bleeding (eTable 5, ESM).

\section{Surgical outcomes}

The median [IQR] length of stay was 7 [5-9] days and the median [IQR] follow-up time between surgery and death or last visit was 2.7 [1.5-4.0] years. The Kaplan-Meier-based median overall survival was 4.8 (95\% CI, 4.3 to 5.7) years; half the cohort had died at 4.8 years. At least one severe postoperative complication (Clavien-Dindo grades III, IV, and V) occurred in 95 of 683 (13.9\%) patients. The 90-day mortality rate was $1.5 \%$ (10/683). Surgical complications and survival were not significantly different in the IOHP or non-IOHP patients (Table 2; eTable 6 and eTable 7, ESM; Fig. 2). Major liver resection ( $\geq$ four segments), combined GI tract surgery, and primary liver cancer were the main factors associated with severe complications (eTable, ESM).

The balanced results of the superpopulations used for our IPTW analyses are found in eTable 8 (ESM).

\section{Discussion}

In this largest to date single-institution cohort analyzing the association between IOHP, transfusion, and outcomes in liver cancer patients, we observed a $14.9 \%$ rate of perioperative RBC transfusion in patients exposed to IOHP compared with $22.4 \%$ in patients without IOHP. The perioperative transfusion rate without IOHP is similar to the findings of another contemporaneous study reporting a transfusion rate of $26.5 \%$ where IOHP was not a standard. ${ }^{4}$ In patients with a predicted risk of $\geq 47.5 \%$ for perioperative transfusion (TRS 2 or 3 ), only $24.6 \%$ were transfused if IOHP was used compared with $56.5 \%$ without IOHP. The IPTW adjusted treatment effect of IOHP supported a significant reduction in transfusion risk on the day of surgery $(\mathrm{aOR}, 0.53 ; 95 \% \mathrm{CI}, 0.29$ to $0.98 ; P=$ 0.04 ), but the effect was not as significant for perioperative transfusions administered during the entire hospital stay. The use of IOHP was safe, and not associated with more postoperative complications, as supported by a recent meta-analysis. ${ }^{29}$

The adversely impacted cancer outcomes observed in transfused patients following hepatectomy ${ }^{3,6-8}$ may be due to transfusion-associated immunomodulation (TRIM), characterized by increased regulatory $\mathrm{T}$ cells, dysfunctions of natural killer cells and macrophages, and deficient antigen presentation, which in turn may impact healing and anti-cancer immunity. ${ }^{30,31}$ Although TRIM may be decreased by depleting allogeneic blood of leukocytes, ${ }^{32,33}$ in the modern era, the benefit of
Fig. 2 One-year overall survival after hepatectomy. Survival curves according to whether or not intraoperative hypovolemic phlebotomy (IOHP) was used, generated from a multivariable marginal Cox modelling adjusted for confounders.

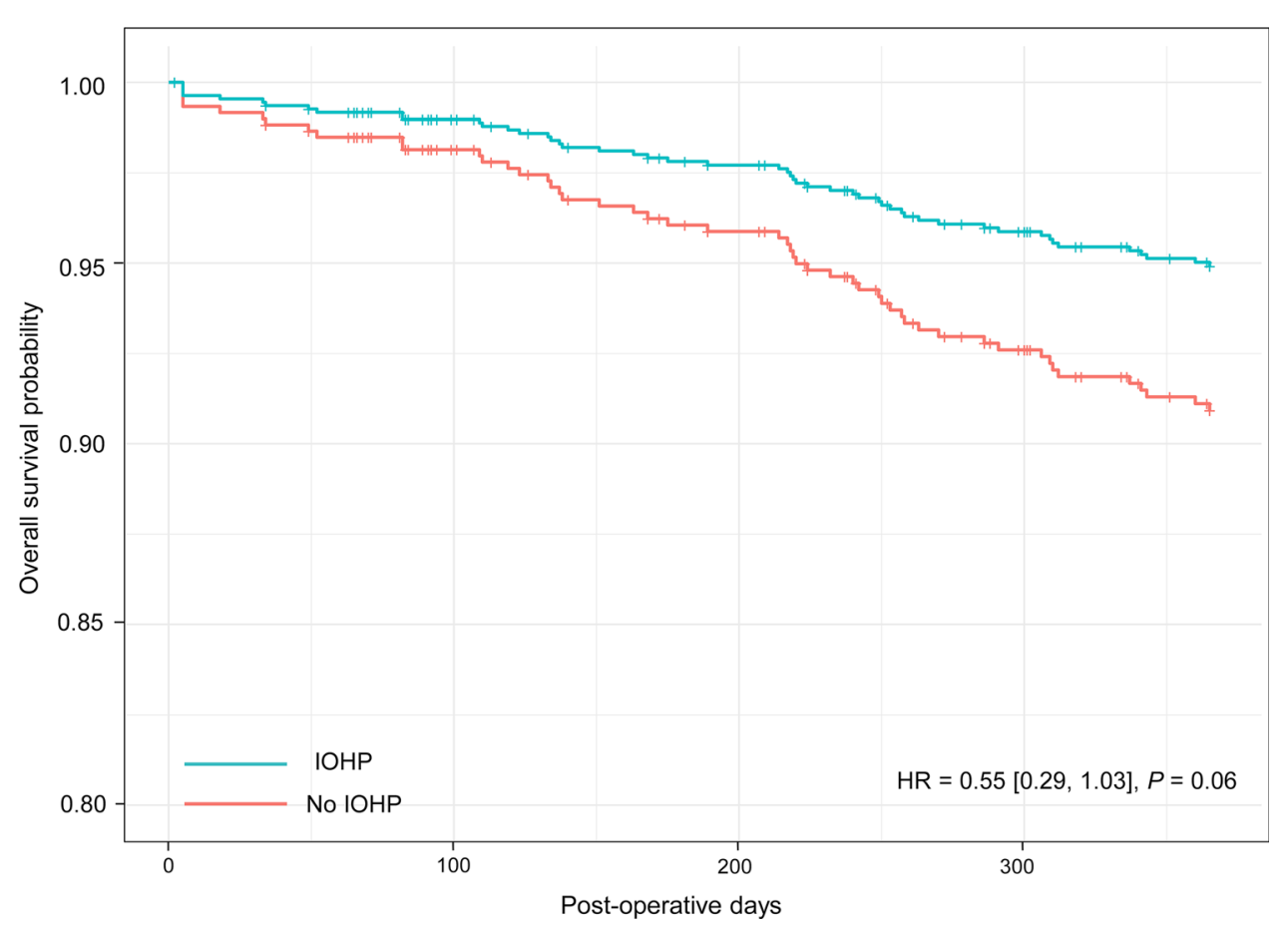


leukoreduced blood products on immunosuppression and cancer recurrence in clinical settings remains unclear. ${ }^{34,35}$ Furthermore, transfusions are associated with rare infections and non-negligible economic costs, ${ }^{36}$ and mistranfusions due to clerical errors are also associated with significant morbidity and mortality. ${ }^{37}$

Preventing RBC transfusion for elective surgery by minimizing surgical blood loss is part of a multi-modal approach of PBM, which is a standard of practice for healthcare institutions according to World Health Organization recommendations. ${ }^{38}$ Several intraoperative techniques have been proposed to reduce bleeding and allogeneic blood transfusion. ${ }^{11-18}$ Of those, low CVP during hepatectomy has been shown to significantly decrease blood loss, one of the main determinants of transfusion. ${ }^{14,15,19-21}$ Due to its low vascular resistance, the liver effectively buffers blood volume. Experimentally, elevation in CVP increases hepatic venous pressure, which results in blood pooling in the liver. ${ }^{21}$ Reducing CVP lowers the pressure in the hepatic veins and their tributaries and minimizes blood loss during parenchymal transection. In contrast, the Pringle maneuver is a very effective inflow occlusion technique that has little influence on backflow bleeding from hepatic veins or their tributaries. Bleeding complicates liver resection by altering the surgeon's view of the transection plane and adjacent important structures, potentially resulting in more blood loss.

The use of IOHP has thus been studied as a means of lowering CVP and reducing blood loss during transection and RBC transfusion requirements. Importantly, IOHP must be distinguished from acute normovolemic hemodilution, where a certain volume of blood is removed and replaced with intravenous fluids to maintain euvolemia, with the phlebotomized blood transfused back to the patient following hepatic transection. ${ }^{39} \mathrm{~A}$ direct association between phlebotomy volume and reduced CVP has been documented, ${ }^{15,19,22,24}$ but IOHP could manifest its beneficial effects independently of CVP. ${ }^{40}$ In 40 patients randomized to undergo a standardized IOHP $(0.7 \%$ of the patient's body weight), a median blood loss of $140 \mathrm{~mL}$ during parenchymal transection was observed compared with $230 \mathrm{~mL}$ in the 39 patients without IOHP $(P=0.03)$, associated with a median CVP of $5 \mathrm{~cm} \mathrm{H}_{2} \mathrm{O}$ vs $6 \mathrm{~cm} \mathrm{H}_{2} \mathrm{O}$ $(P=0.005)$, respectively. ${ }^{40}$ In this study, the total intraoperative blood loss was, however, not significantly different between the two groups. Ryckx et al. ${ }^{19}$ specifically recorded the drop in CVP associated with IOHP in 100 consecutive patients undergoing liver resection. By multivariate analysis, the drop in CVP (median [IQR], 5 [0-14] $\mathrm{mmHg}$ ) and the IOHP volume (median [IQR], 400 [200-1,000] $\mathrm{mL}$ ) were both significantly associated with a lower intraoperative blood loss $(P=0.001)$.

Consistently, in the sensitivity analyses we conducted, dichotomizing for large $v s$ small IOHP using a median of $5.25 \mathrm{~mL} \cdot \mathrm{kg}^{-1}$ patient weight as a cut-off value, suggested that small IOHP had no effect on perioperative transfusion (OR, $1.03 ; 95 \% \mathrm{CI}, 0.53$ to $1.98 ; P=0.94$ ) compared with large IOHP (OR, $0.58 ; 95 \% \mathrm{CI}, 0.31$ to $1.10 ; P=0.10)$. We could not retrieve data on the CVP drop for analysis in our study. The median [IQR] intraoperative blood loss of 500 [250-800] $\mathrm{mL}$ we observed falls within the range of 0 to $2,100 \mathrm{~mL}$ and median values of approximately 400 to $500 \mathrm{~mL}$ reported in IOHP studies. Despite adjustment for confounders, IOHP was not associated with lower intraoperative blood loss. In this retrospective study, blood loss estimated at time of surgery was subjective and not standardized, limiting the accuracy and relevance of this outcome. We may also have observed a stronger effect of IOHP on bleeding and transfusion outcomes if the median phlebotomized blood volume normalized for patient weight had been higher than $5.25 \mathrm{~mL} \cdot \mathrm{kg}^{-1}$ and within the published target of 7-10 $\mathrm{mL} \cdot \mathrm{kg}^{-1} \cdot 15,41$ Practical factors may have contributed to the relatively small IOHP volume we observed, since the median volume of $396 \mathrm{~mL}$ roughly corresponds to the volume of a single blood procurement bag.

Our study has limitations inherent to the retrospective design. Although the clinical and transfusion databases were prospectively maintained, the IOHP data were retrospectively extracted from anesthesiology charts. There were no systematic explanations reported to justify why a smaller than expected phlebotomy was performed, or no phlebotomy at all. Outside a prospective trial, the decision to transfuse a patient during and after a hepatectomy and the estimated intraoperative blood loss involves many subjective factors that we could not control for and that may be associated with our exposure of interest. Although we adjusted the analyses for many confounders, we cannot exclude uncontrolled confounding. Even though we fitted multiple models to better define the association between IOHP and outcomes, the model fitted by IPTW was the one with fewer model assumptions and greater precision.

\section{Conclusions}

In 522 consecutive partial hepatectomies, IOHP was found to be safe, associated with fewer RBC transfusions on the day of surgery, and less perioperative RBC transfusions than expected according to predictive scoring and published data. Randomized-controlled trials comparing IOHP with other anesthesia techniques are 
needed to help standardize practices of low CVP and to optimize perioperative blood management for liver surgery.

Author contributions Maher Al Khaldi, Filip Gryspeerdt, Simon Turcotte, and François Martin Carrier contributed to study conception and design, data acquisition, analysis and interpretation, drafting and finalizing the manuscript. Claudia Bouchard and Benjamin Rioux-Massé contributed to blood transfusion data acquisition and analysis. Zhixia Rong, Ève Simoneau, Marylène Plasse, Richard Létourneau, Michel Dagenais, André Roy, Réal Lapointe, Luc Massicotte, Franck Vandenbroucke-Menu, and Benjamin Rioux-Massé contributed to data interpretation and critical manuscript revision.

Acknowledgements We thank L. Rousseau, S. Langevin, and J. Bilodeau from the CHUM Hepatopancreatobiliary and Colorectal Cancer Database \& Biobank for patient recruitment and prospective data maintenance. This study was funded by the Chaire Roger Des Groseillers en oncologie chirurgicale hépatobiliaire et pancréatique de l’Université de Montréal.

\section{Disclosures None.}

Funding statement Chaire Roger Des Groseillers en oncologie chirurgicale hépatobiliaire et pancréatique de l'Université de Montréal. Dr. Turcotte and Dr. Carrier are recipients of a Career Award from the Fonds de Recherche du Québec - Santé.

Editorial responsibility This submission was handled by Dr. Hilary P. Grocott, former Editor-in-Chief, Canadian Journal of Anesthesia.

Open Access This article is licensed under a Creative Commons Attribution-NonCommercial 4.0 International License, which permits any non-commercial use, sharing, adaptation, distribution and reproduction in any medium or format, as long as you give appropriate credit to the original author(s) and the source, provide a link to the Creative Commons licence, and indicate if changes were made. The images or other third party material in this article are included in the article's Creative Commons licence, unless indicated otherwise in a credit line to the material. If material is not included in the article's Creative Commons licence and your intended use is not permitted by statutory regulation or exceeds the permitted use, you will need to obtain permission directly from the copyright holder. To view a copy of this licence, visit http://creativecommons.org/licenses/ by-nc/4.0/.

\section{References}

1. Creasy JM, Sadot E, Koerkamp BG, et al. Actual 10-year survival after hepatic resection of colorectal liver metastases: what factors preclude cure? Surgery 2018; 163: 1238-44.

2. Kingham TP, Correa-Gallego C, D'Angelica MI, et al. Hepatic parenchymal preservation surgery: decreasing morbidity and mortality rates in 4,152 resections for malignancy. J Am Coll Surg 2015; 220: 471-9.

3. Kooby DA, Stockman J, Ben-Porat L, et al. Influence of transfusions on perioperative and long-term outcome in patients following hepatic resection for colorectal metastases. Ann Surg 2003; 237: 860-70.

4. Lemke M, Law CH, Li J, et al. Three-point transfusion risk score in hepatectomy. Br J Surg 2017; 104: 434-42.

5. Spolverato G, Ejaz A, Kim Y, et al. Patterns of care among patients undergoing hepatic resection: a query of the National Surgical Quality Improvement Program-targeted hepatectomy database. J Surg Res 2015; 196: 221-8.

6. Amato A, Pescatori M. Perioperative blood transfusions and recurrence of colorectal cancer. Cochrane Database Syst Rev 2006. DOI: https://doi.org/10.1002/14651858.CD005033.pub2.

7. Bennett $S$, Baker LK, Martel G, et al. The impact of perioperative red blood cell transfusions in patients undergoing liver resection: a systematic review. HPB (Oxford) 2017; 19: 321-30.

8. Hallet J, Tsang M, Cheng ES, et al. The impact of perioperative red blood cell transfusions on long-term outcomes after hepatectomy for colorectal liver metastases. Ann Surg Oncol 2015; 22: 4038-45.

9. Brustia R, Granger B, Scatton O. An update on topical haemostatic agents in liver surgery: systematic review and meta analysis. J Hepatobiliary Pancreat Sci 2016; 23: 609-21.

10. Carless PA, Henry DA, Moxey AJ, O'Connell D, Brown T, Fergusson DA. Cell salvage for minimising perioperative allogeneic blood transfusion. Cochrane Database Syst Rev 2003. DOI: https://doi.org/10.1002/14651858.CD001888.

11. Gurusamy KS, Li J, Vaughan J, Sharma D, Davidson BR. Cardiopulmonary interventions to decrease blood loss and blood transfusion requirements for liver resection. Cochrane Database Syst Rev 2012. DOI: https://doi.org/10.1002/14651858. CD007338.pub3.

12. Gurusamy KS, Pamecha V, Sharma D, Davidson BR. Techniques for liver parenchymal transection in liver resection. Cochrane Database Syst Rev 2009. DOI: https://doi.org/10.1002/14651858. CD006880.pub2.

13. Gurusamy KS, Kumar Y, Ramamoorthy R, Sharma D, Davidson $B R$. Vascular occlusion for elective liver resections. Cochrane Database Syst Rev 2009. DOI: https://doi.org/10.1002/14651858. CD007530.

14. Hughes MJ, Ventham NT, Harrison EM, Wigmore SJ. Central venous pressure and liver resection: a systematic review and meta-analysis. HPB (Oxford) 2015; 17: 863-71.

15. Rekman $J$, Wherrett $C$, Bennett $S$, et al. Safety and feasibility of phlebotomy with controlled hypovolemia to minimize blood loss in liver resections. Surgery 2017; 161: 650-7.

16. Sanjay $P$, Watt DG, Wigmore SJ. Systematic review and metaanalysis of haemostatic and biliostatic efficacy of fibrin sealants in elective liver surgery. J Gastrointest Surg 2013; 17: 829-36.

17. Waters JH, Yazer M, Chen Y, Kloke J. Blood salvage and cancer surgery: a meta-analysis of available studies. Transfusion 2012; 50: 2167-73.

18. Moggia E, Rouse B, Simillis C, et al. Methods to decrease blood loss during liver resection: a network meta-analysis. Cochrane Database Syst Rev 2016. DOI: https://doi.org/10.1002/14651858. CD010683.pub3.

19. Ryckx A, Christiaens C, Clarysse $M$, et al. Central venous pressure drop after hypovolemic phlebotomy is a strong independent predictor of intraoperative blood loss during liver resection. Ann Surg Oncol 2017; 24: 1367-75.

20. Jones RM, Moulton CE, Hardy KJ. Central venous pressure and its effect on blood loss during liver resection. Br J Surg 1998; 85: 1058-60.

21. Lautt $W W$, Greenway $C V$. Hepatic venous compliance and role of liver as a blood reservoir. Am J Physiol 1976; 231: 292-5.

22. Baker L, Bennett S, Rekman J, et al. Hypovolemic phlebotomy in liver surgery is associated with decreased red blood cell transfusion. HPB (Oxford) 2018; 21: 757-64. 
23. Putchakayala K, DiFronzo LA. Acute hemodilution is safe in patients with comorbid illness undergoing partial hepatectomy. Am Surg 2013; 79: 1093-7.

24. Massicotte L, Lenis $S$, Thibeault L, Sassine MP, Seal RF, Roy A. Effect of low central venous pressure and phlebotomy on blood product transfusion requirements during liver transplantations. Liver Transpl 2006; 12: 117-23.

25. Dindo D, Demartines N, Clavien PA. Classification of surgical complications: a new proposal with evaluation in a cohort of 6336 patients and results of a survey. Ann Surg 2004; 240: 205-13.

26. Rahbari NN, Garden OJ, Padbury R, et al. Posthepatectomy liver failure: a definition and grading by the International Study Group of Liver Surgery (ISGLS). Surgery 2011; 149: 713-24.

27. Kleinbaum DG, Klein M. Stat Biol Health - Survival Analysis: A Self-Learning Text, Third Edition. Springer; 2011.

28. Robins JM, Hernán MÁ, Brumback B. Marginal structural models and causal inference in epidemiology. Epidemiology 2000; 11: 550-60.

29. Park L, Gilbert R, Baker L, et al. The safety and efficacy of hypovolemic phlebotomy on blood loss and transfusion in liver surgery: a systematic review and meta-analysis. HPB (Oxford) 2020; 22: 340-50.

30. Blajchman MA. Immunomodulation and blood transfusion. Am J Ther 2002; 9: 389-95.

31. Goubran HA, Elemary M, Radosevich M, Seghatchian J, ElEkiaby M, Burnouf T. Impact of transfusion on cancer growth and outcome. Cancer Growth Metastasis 2016; 9: 1-8.

32. Bordin JO, Bardossy L, Blajchman MA. Growth enhancement of established tumors by allogeneic blood transfusion in experimental animals and its amelioration by leukodepletion: the importance of the timing of the leukodepletion. Blood 1994; 84: 344-8.

33. Blajchman MA, Bardossy L, Carmen R, Sastry A, Singal DP. Allogeneic blood transfusion-induced enhancement of tumor growth: two animal models showing amelioration by leukodepletion and passive transfer using spleen cells. Blood 1993; 81: 1880-2.

34. Vamvakas EC, Blajchman MA. Transfusion-related immunomodulation (TRIM): an update. Blood Rev 2007; 21: 327-48.

35. Jensen LS, Puho E, Pedersen L, Mortensen FV, Sørensen HT. Long-term survival after colorectal surgery associated with buffycoat-poor and leucocyte-depleted blood transfusion: a follow-up study. Lancet 2005; 365: 681-2.

36. Madjdpour C, Spahn DR. Allogeneic red blood cell transfusions: efficacy, risks, alternatives and indications. Br J Anaesth 2005; 95: 33-42.

37. Williamson LM, Lowe S, Love EM, et al. Serious hazards of transfusion (SHOT) initiative: analysis of the first two annual reports. BMJ 1999; 319: 16-9.

38. World Health Organization; Blood Transfusion Safety Team. The Clinical Use of Blood: Handbook. World Health Organization; 2001.

39. Jarnagin WR, Gonen M, Maithel SK, et al. A prospective randomized trial of acute normovolemic hemodilution compared to standard intraoperative management in patients undergoing major hepatic resection. Ann Surg 2008; 248: 360-9.

40. Hashimoto $T$, Kokudo $N$, Orii $R$, et al. Intraoperative blood salvage during liver resection: a randomized controlled trial. Ann Surg 2007; 245: 686-91.

41. Martel G, Baker L, Wherrett $C$, et al. Phlebotomy resulting in controlled hypovolaemia to prevent blood loss in major hepatic resections (PRICE-1): a pilot randomized clinical trial for feasibility. Br J Surg 2020; 107: 812-23.

Publisher's Note Springer Nature remains neutral with regard to jurisdictional claims in published maps and institutional affiliations. 